\title{
Damerect \\ Open Government Data Use in the Brazilian States and Federal District Public Administrations
}

\author{
Ilka Kawashita ${ }^{1, *(\mathbb{D}}$, Ana Alice Baptista ${ }^{2} \mathbb{D}$ and Delfina Soares ${ }^{3}$ \\ 1 College of Business and IT, University of Phoenix, Phoenix, AZ 85040, USA \\ 2 Algoritmi Center, University of Minho, 4800-058 Guimarães, Portugal; analice@dsi.uminho.pt \\ 3 Operating Unit on Policy-Driven Electronic Governance (UNU-EGOV), United Nations University, \\ 4810-225 Guimarães, Portugal; soares@unu.edu \\ * Correspondence: ikawashita@email.phoenix.edu
}

\section{check for}

updates

Citation: Kawashita, I.; Baptista, A.A.; Soares, D. Open Government Data Use in the Brazilian States and Federal District Public

Administrations. Data 2022, 7, 5. https://doi.org/10.3390/data7010005

Received: 8 November 2021 Accepted: 24 December 2021 Published: 5 January 2022

Publisher's Note: MDPI stays neutral with regard to jurisdictional claims in published maps and institutional affiliations.

Copyright: (c) 2022 by the authors. Licensee MDPI, Basel, Switzerland. This article is an open access article distributed under the terms and conditions of the Creative Commons Attribution (CC BY) license (https:// creativecommons.org/licenses/by/ $4.0 /)$.

\begin{abstract}
This research investigates whether, why, and how open government data (OGD) is used and reused by Brazilian state and district public administrations. A new online questionnaire was developed and collected data from 26 of the 27 federation units between June and July 2021. The resulting dataset was cleaned and anonymized. It contains an insight on 158 parameters for 26 federation units explored. This article describes the questionnaire metadata and the methods applied to collect and treat data. The data file was divided into four sections: respondent profile (identify the respondent and his workplace), OGD use/consumption, what OGD is used for by public administrations, and why OGD is used by public administrations (benefits, barriers, drivers, and barriers to OGD use/reuse). Results provide the state of the play of OGD use/reuse in the federation units administrations. Therefore, they could be used to inform open data policy and decision-making processes. Furthermore, they could be the starting point for discussing how OGD could better support the digital transformation in the public sector.
\end{abstract}

Dataset: https://doi.org/10.34622/datarepositorium/UY7MFA.

Dataset License: CCO.

Keywords: open government data; benefits; barriers; enablers; drivers; public sector; use; reuse; open data; Brazil

\section{Introduction}

Public institutions produce, collect, and aggregate vast amounts of data and publish it as open (government) data [1]. According to Open Definition, open data can be freely used, reused, modified, and shared by anyone for any purpose. Given its potential, open data provides opportunities for governments worldwide to implement some of their digital transformation processes [2].

Furthermore, open government data (OGD) has the potential to improve operations efficiency, evidence-based and data-driven policymaking and increase transparency, accountability, civil participation, and trust in government. Despite its benefits, OGD has not been extensively adopted in public sector organizations, particularly in developing countries [3]. The literature provides insights into the barriers to OGD adoption, sharing, use, and reuse. Through a global survey, Zuiderwijk and Reuver [4] identified seven barriers to OGD initiatives: functionality and support; inclusiveness; economy, policy, and process; data interpretation; data quality and resources; legislation and access; and sustainability. In another study, Crusoe and Melin [5] conducted a systematic literature review to investigate the OGD barriers. Studies focused on technical, organizational, and legal barrier types, while studies on open data usage and systems were less frequent. Forty-six barriers were categorized to an expanded OGD process (suitability, release, publish, use, and evaluation). 
The literature also offers insights into determinants that influence the OGD adoption in public sector organizations [3].

However, the use of OGD for government is incipient [6], and studies addressing the use of OGD are scarce [3]. Therefore, this project investigates whether, how, and why open government data is used and reused by the Brazilian states and district public administrations. Thus, a survey was developed to collect information from digital government leaders of Brazilian federation units (FUs) public administrations. The term "use" means data use, reuse, or consumption in opposition to data adoption, release, or publication.

This research project was executed by the University of Minho (UM) and the University of the United Nations (UNU-EGOV), with the support of the Digital Transformation Group of States and Federal District (DF)-(GTD.GOV). The GTD.GOV is a national network that gathers specialists in digital transformation from state and district governments across the country. Its mission is to accelerate Brazilian states and district governments' digital transformation [7]. The group was created by the Brazilian Association of State Entities of Information Technology and Communication (ABEP-TIC) and the National Council of State Secretaries of Administration (CONSAD).

ABEP-TIC brings together all state information technology and communication companies in Brazil. It seeks to influence public policies in all spheres of government to promote and strengthen cooperation among its associates. Furthermore, ABEP-TIC fosters administrative modernization to improve the quality and productivity of state government services [8]. In addition, CONSAD congregates the secretaries of state for administration of all 26 Brazilian States and the federal district to exchange experiences and seek creative solutions to improve public management in Brazil [9].

Brazil has been relatively successful in opening data. Given the increasing deployment of digital services, the Brazilian public administrations have produced an increasing set of government data in open format. According to the State Basic Information Survey (Estadic 2019) [10], all federation units have a transparency portal and publish general administration data in a reuse-friendly format and other formats. For example, 84.0\% (21) of the $25 \mathrm{FUs}$ published expenditure information in a more reuse-friendly format, while only $18.5 \%$ (5) of the 27 did so for accountability of the Fiscal Responsibility Act (LRF).

In addition, a recent survey on digital transformation trends in Brazilian state governments and the federal district [11] indicated that 19 of the 26 Brazilian states have open data portals. However, only eight have legislation which allow state public administration to share data among its agencies. Since OGD is already published and is an integral part of the digital transformation of public administrations, it is necessary to understand whether, for what, and why OGD is used. Moreover, if they are not used, understand the barriers and factors that could facilitate and drive data use and reuse.

Results provide an overview of OGD use and could inform open data policy and decision-making processes in the states and district public administrations. In addition, they provide the basis for further discussion about how OGD can be used and reused to support the digital transformation of the public sector.

The remaining of this article is organized as follows. First, Section 2 presents the methods applied to collect and treat the data. Next, Section 3 describes the questionnaire. Finally, the results and conclusion are presented in Section 4.

\section{Methods}

This project (CEICSH 069/2021) was submitted to and approved by the Ethics Committee for Research in Social and Human Sciences (CEICSH) of the University of Minho (UM) on 22 June 2021. Personal data, such as IP address, emails, gender, and age, were collected. However, these data were anonymized to prevent individual respondent identification.

Our objective is to investigate whether, how, and why the public sector uses open government data. Therefore, given the exploratory, inductive nature of the work, we adopted the survey research method. It is used for collecting data from a representative sample of individuals to describe the behaviors, thoughts, and attitudes at a specific 
place and time. An instrument (questionnaire) composed of closed-ended and openended questions was developed as discussed in [12]. A systematic review of the literature, conducted according to $[13,14]$ served to identify research gaps and support the creation of the survey.

From the literature review [15] we collected and systematized the categories of data used and what OGD is used for. We also gathered OGD use benefits, barriers, drivers, and enablers (BBDE) reported in these studies. Therefore, the following categories to classify BBDE were synthesized: political and social, legal and public policy, cultural, economic and financial, organizational and institutional, and technical and operational). Finally, questionnaire questions were developed based on the BBDE literature reported in [15], which adopted the abovementioned BBDE categorization. In summary, the review was the foundation of this survey and its online questionnaire.

Table 1 presents additional information on the questionnaire creation and application.

Table 1. Additional information about the questionnaire.

\begin{tabular}{ll}
\hline \multicolumn{1}{c}{ Questionnaire } & \multicolumn{1}{c}{ Description } \\
\hline Application mode & $\begin{array}{l}\text { Unsupervised online tool using LimeSurvey tool Version 3.25.6+201229. Respondents } \\
\text { answered the questionnaire by themselves using the LimeSurvey software. }\end{array}$ \\
\hline Research of the relevant literature & $\begin{array}{l}\text { The uses, benefits, barriers, drivers, and enablers (BBDE) listed are derived from a } \\
\text { systematic literature review [15]. }\end{array}$ \\
\hline Construction of the questionnaire & $\begin{array}{l}\text { The new questionnaire consists of 39 questions divided into seven groups. Questions and } \\
\text { grouping categories were derived from a review of mainly English literature. Then, the } \\
\text { questionnaire was developed in the LimeSurvey software, which supports the creation of } \\
\text { multilingual surveys. The questionnaire was created in English and then translated to } \\
\text { Portuguese. Therefore, two versions of the same questionnaire exist, one in English and } \\
\text { another in Portuguese. Metadata is available in both languages. Worth noting that } \\
\text { respondents answered the Portuguese questionnaire version. Therefore, data was } \\
\text { collected in Portuguese. The English version is used to report results. }\end{array}$ \\
\hline
\end{tabular}

The questionnaire in Portuguese was applied to a sample of five people working with OGD (faculty members in higher education and master level students in Brazil) between

Pretest April and May 2021. As a result, questions were improved for language use and content. In addition, the logic flow was adjusted before the final application based on pretest results and suggestions. The English version was also adjusted to match the tested version.

Sampling method

Non-probabilistic [16]. The GTD.GOV indicated their focal points: Brazilian state and district administration secretaries, managers responsible for the open data area in the state administration, and state and district public managers who use OGD. The "snowball" strategy [17], which requests the indication of additional participants to the respondents, was also used.

The GTD.GOV selected 49 digital transformation state and district officials that were invited by email to contribute with the survey. A total of 61 responses were collected. Thirty responses were incomplete and were removed from the sample. Thirty-one responses were complete (the last page column equals 7 , the number of pages of the questionnaire).

All 27 federation units were invited to participate in this research, and 26 answered the questionnaire. The exception was the State of São Paulo, which declined to respond the questionnaire. Consequently, the dataset does not contain any data for São Paulo. This

Sample size survey collected data from several State secretariats and agencies, such as administration, planning, information technology, and internal control. Their responses offer the state perspective as the leaders of the State's digital transformation, and open data policy is allocated in them. In the case of states with more than one response, the Secretariat of Administration or Planning record was selected because these secretariats are responsible for the open data policy. They are also and are the loci of CONSAD focal points. Moreover, in the case of more than one complete response per respondent, only the last data (the newest date last action column) was kept. Therefore, this sample contains 26 records, one response per federation unit, which represent the answer of the FU. 
Table 1. Cont.

\begin{tabular}{ll}
\hline \multicolumn{1}{c}{ Questionnaire } & \multicolumn{1}{c}{ Description } \\
\hline \multirow{2}{*}{ Target population } & $\begin{array}{l}\text { GTD.GOV indicated participants from their focal points. That includes Brazilian state and } \\
\text { district administration secretaries, managers responsible for the open data area in the state } \\
\text { administration, and state and d district public managers who use open government data. } \\
\text { The language used was Portuguese. }\end{array}$ \\
\hline Recruitment and screening & Invitations and requests were made by email. \\
\hline Data collection period & 10 June to 9 July 2021 \\
\hline
\end{tabular}

\section{Data Cleaning}

After applying the questionnaire on the LimeSurvey platform, responses were exported and consolidated in an Excel spreadsheet in a tabular format. Data were collected in Portuguese. Data were cleaned and adjusted to fit in a row (regroup fields separated during the import to Excel process due to the use of commas in text input by respondents). Metadata in Portuguese and English were also imported and added to the spreadsheet. Then, answers to close-ended questions were translated to English and placed in a spreadsheet with English metadata. Open-ended questions which hold respondent inputted data were not translated to preserve originality and avoid introducing researchers' biases. The dataset is available as a CSV file in an open format [18]. The dataset is composed of five CSV files and one Excel (XLST) file, as detailed in the Supplementary Material.

\section{Data Description}

This section describes the data collected according to the method presented in Section 3. Each column of the data table, what data are contained, their format, how to read and interpret data are defined.

The aim of this research is to investigate whether, for what, and why the public sector uses/consumes OGD. To collect information, a survey invited Brazilian State and District government leaders to respond to a new online questionnaire that is composed of four analytical sections, as shown in Table 2.

Table 2. Questionnaire analytical structure.

\begin{tabular}{ll}
\hline \multicolumn{1}{c}{ Questionnaire Sections } & \multicolumn{1}{c}{ Description } \\
\hline Section I-Respondent Profile & Identify the respondent and his workplace \\
\hline Section II-OGD use/reuse & $\begin{array}{l}\text { If public administrations use OGD, then ask for public context } \\
\text { (default: State) and State name } \\
\text { If OGD is not used, then ask why data are not used }\end{array}$ \\
\hline \multirow{2}{*}{ Section III-What is OGD used for by public administrations? } & $\begin{array}{l}\text { Data are used for what? } \\
\text { What are the categories of data used? } \\
\text { Name of the institutions that provide the data (data sources) }\end{array}$ \\
\hline & $\begin{array}{l}\text { Benefits and negative impacts caused by OGD use } \\
\text { Barriers: factors preventing or hindering OGD consumption } \\
\text { Dection IV—Whers: factors that drive or mandate OGD use } \\
\text { Enablers: factors that facilitate, enable, or allow the use of OGD }\end{array}$ \\
\hline
\end{tabular}

The questionnaire was applied between 10 June and 9 July 2021. The resulting dataset comprises 26 rows, one for each federation unit excepting the State of São Paulo, which was the only State that declined to participate in the survey. Thus, this dataset represents the perspective of the 26-participating federation units. Responses were exported to Excel in a tabular format. The dataset contents are summarized in Table 3. 
Table 3. Dataset information.

\begin{tabular}{ll}
\hline Column & Description \\
\hline Last updated & 5 October 2021 \\
\hline Dataset created & 29 July 2021 \\
\hline Data collected & Between June 10 and 9 July 2021 \\
\hline Dataset owner & Ilka Kawashita \\
\hline License & https://creativecommons.org/publicdomain/zero/1.0/ (accessed on 26 December 2021) \\
\hline Source link & https://doi.org/10.34622/datarepositorium/UY7MFA (accessed on 27 December 2021) \\
\hline Encoding & Unicode (UFT-8) \\
\hline Rows & 26 \\
\hline Columns & 158 \\
\hline
\end{tabular}

Each row of the dataset lists the responses to a questionnaire about the use (consumption) of open government data (OGD) in the Brazilian states and federal district public administrations. The questionnaire was applied between June 10 and 9 July 2021, in a sample composed of focal points designated by the GTD.GOV. The dataset contains 26 lines, one response per Federation Unit,

Dataset description except for the State of São Paulo that chose to not answer the survey. Thus, this dataset represents the perspective of each federation unit that participated in the survey. Respondents were instructed to offer the view of their federation unit, as they are state officials responsible for open data in their administrations. After collection, data were exported to Excel. The resulting dataset was cleaned and is in a table format.

The questionnaire is composed of simple and multiple-choice questions. In addition, some of the questions include an extra field for text comments.

\begin{tabular}{ll}
\hline Simple questions & Naming convention \\
\hline Example & QuestionId. QuestionLabel. \\
\hline "Q005. In which public context does your institution/agency operate? \\
If municipal or regional, please inform it in the comments field"
\end{tabular}

Column naming convention 
Table 3. Cont.

\begin{tabular}{ll}
\hline Column & Description \\
\hline & Each column is described in the remaining of this section. As the metadata refers to the \\
questionnaire questions, many column names are self-explaining. Since the dataset is in tabular \\
format, the following metadata is presented: column name, a short description (when needed), \\
datatype, possible data values, mandatory/optional indicator. This information is also provided in \\
the dataset in two sheets: Metadata_PT and Metadata_EN. In the first sheet, metadata is provided \\
in Portuguese, and the second in English. \\
To prevent respondents' identification, the columns ipaddr. IP address, Q00. Name, Q001. Email, \\
Q002. Age, Q003. Gender and Q155[Comment] were anonymized. The term "anonymized" \\
replaced the actual values. \\
description
\end{tabular}

Metadata was divided and is presented into seven tables. Data generated and collected by the system are in Table 4 . The remaining tables correspond to data collected using the questionnaire. The respondent profile is listed in Table 5. Table 6 contains data about whether open government data (OGD) are used and for what data are used. Tables 7-10 show respectively the questions related to OGD use benefits, barriers, enablers, and drivers. Columns are presented in the same order they appear in the dataset.

Table 4 presents information generated by the LimeSurvey software. All columns are mandatory. Note that the column ipaddr. IP address, which has the IP address of the respondent's device, was anonymized.

Table 4. Data generated by the LimeSurvey software.

\begin{tabular}{lll}
\hline \multicolumn{1}{c}{ Column Name } & \multicolumn{1}{c}{ Description } & Datatype \\
\hline id. Response ID & Response unique identifier & Number \\
\hline submitdate. Date submitted & Date the questionnaire was submitted & Date/time \\
\hline lastpage. Last page & $\begin{array}{l}\text { Last page of the questionnaire that the respondent reached. } \\
\text { Possible values }[-1,0, \ldots, 7] . \text { Between }-1 \text { and } 6 \text { means it is } \\
\text { incomplete; } 7 \text { is the last page of a completed questionnaire. This } \\
\text { sample only shows completed questionnaires. }\end{array}$ & Number \\
\hline startlanguage. Start language & Questionnaire start language & Text \\
\hline seed. Seed & Seed number generated by the system & Number \\
\hline startdate. Date started & The date that the respondent started the questionnaire & Date/time \\
\hline datestamp. Date last action & Date of the respondent last action & Date/time \\
\hline ipaddr. IP address & Respondent device IP address & Text \\
\hline
\end{tabular}

Table 5 shows the questions of the respondent profile section. All columns are mandatory, except for the respondent's name, email, and Q005[comment]. Due to the small size of this sample, it would be possible to identify respondents based on age and gender. Consequently, the following columns were anonymized Q00. Name, Q001. Email, Q002. Age, and Q003. Gender. 
Table 5. Respondent profile metadata.

\begin{tabular}{llll}
\hline Column Name & Description & Datatype & Data Values \\
\hline Q00. Name: & Respondent name & Text & \\
\hline Q001. Email: & Respondent email & Text & \\
\hline Q002. Age & Respondent age range & $\begin{array}{l}\text { List: [less than 25 years, } \\
\text { between } 25 \text { and 39 years, } \\
\text { between } 40 \text { and 54 years, equal or } \\
\text { more than 55 years] }\end{array}$ \\
\hline Q003. Gender & Respondent gender & Text & $\begin{array}{l}\text { List: [female, male, I do not want to } \\
\text { inform] }\end{array}$ \\
\hline
\end{tabular}

Q004. Which public institution/agency do you work for?

Name of the respondent workplace Text

Q005. In which public context does your institution/agency operate? If Indicates the public context that the municipal or regional, please inform institution/agency the responded works operate it in the comments field.

Field to input the municipality or region that agency/institution of Q005 operates
Text operate? If municipal or regional, please inform it in the comments field. [Comment]

\author{
List: [Acre, Alagoas, Amapá, \\ Amazonas, Bahia, Ceará, Distrito \\ Federal, Espírito Santo, Goiás, \\ Maranhão, Mato Grosso, Mato \\ Grosso do Sul, Minas Gerais, Pará, \\ Paraíba, Paraná, Pernambuco, Piauí, \\ Rio de Janeiro, Rio Grande do Norte, \\ Rio Grande do Sul, Rondônia, \\ Roraima, Santa Catarina, São Paulo, \\ Sergipe, Tocantins]
} Brazilian state where the

Text respondent works
Q006. State

Table 6 describes three blocks of questions: if data are used, what data are used for, and why these data are not used. Each question corresponds to a column in the dataset. Q100 determines whether OGD is used. Then, if data are used, Q106, Q105, and Q104 explore what data are used for, the categories of data consumed, and the institutions that provide OGD. These questions were reversed to improve the questionnaire logic flow. Lastly, if OGD is not used, Q150 and Q151 investigate the reasons for not using OGD.

Q155 implements the snowball sampling strategy. It requests the respondent to inform the email of people who could collaborate with the study if the person could not. Q155. [Comment] was anonymized as it may have email addresses.

Table 6. Metadata of open government data use/reuse and what data used is for sections.

\begin{tabular}{lcc}
\hline \multicolumn{1}{c}{ Column Name } & Description & Datatype \\
\hline $\begin{array}{l}\text { Q100. Is Open Government Data (OGD) used } \\
\text { internally at your institution/agency? }\end{array}$ & $\begin{array}{l}\text { Q100 is mandatory Possible responses [Yes, no, I } \\
\text { do not know] }\end{array}$ & Text \\
\hline $\begin{array}{l}\text { Question Q106. What is Open Government Data (OGD) used for internally? Optional multiple-choice question. Response datatype: } \\
\text { text. Possible responses [Yes, No, N/A]. N/A = Not answered. }\end{array}$ & \\
\hline Column name and description & \\
\hline $\begin{array}{l}\text { Q106[SQ002]. What are open government data (OGD) used for internally? [Data analysis (analyses, forecasts, estimates, } \\
\text { simulations, models)] }\end{array}$ \\
\hline
\end{tabular}


Table 6. Cont.

\section{Column Name}

Description

Datatype

Q106[SQ003]. What are open government data (OGD) used for internally? [Support environmental management (quality and level of water pollution)]

Q106[SQ004]. What are open government data (OGD) used for internally? [Support emergencies (fires, floods) management and prevention]

Q106[SQ005]. What are open government data (OGD) used for internally? [Support accountability]

Q106[SQ006]. What are open government data (OGD) used for internally? [Support decision-making]

Q106[SQ007]. What are open government data (OGD) used for internally? [Support government operations management (fleet, energy consumption, water, gas)]

Q106[SQ008]. What are open government data (OGD) used for internally? [Increase (administrative, legal, legislative) procedures transparency]

Q106[SQ009]. What are open government data (OGD) used for internally? [Increase the efficiency of service delivery changes]

Q106[SQ010]. What are open government data (OGD) used for internally? [Co-create products and services]

Q106[SQ011]. What are open government data (OGD) used for internally? [Combine, connect, and/or create new datasets]

Q106[SQ012]. What are open government data (OGD) used for internally? [Create/improve public services]

Q106[SQ013]. What are open government data (OGD) used for internally? [Develop web, mobile applications]

Q106[SQ014]. What are open government data (OGD) used for internally? [Develop/improve other products]

Q106[SQ015]. What are open government data (OGD) used for internally? [Develop/improve visualizations (maps, location,

dashboards)]

Q106[SQ016]. What are open government data (OGD) used for internally? [Services digitalization]

Q106[SQ017]. What are open government data (OGD) used for internally? [Inform public policies development]

Q106[SQ018]. What are open government data (OGD) used for internally? [Inform planning]

Q106[SQ019]. What are open government data (OGD) used for internally? [Promote systems interoperability]

Q106[SQ020]. What are open government data (OGD) used for internally? [Provide better access to public services]

Column Name Description Datape

Q1061. Are open government data (OGD) used for Field to inform whether open government data

other purposes? Which?

(OGD) is used for other purposes

Text

Question 105. What are the categories of open government data (OGD) used at your institution? Optional Multiple-choice question.

Response datatype: text. Possible responses [Yes, No, N/A]. N/A = Not answered.

Column name and description

Q105[SQ001]. What are the categories of open government data (OGD) used at your institution? [Procurement]

Q105[SQ002]. What are the categories of open government data (OGD) used at your institution? [Crime]

Q105[SQ003]. What are the categories of open government data (OGD) used at your institution? [Public expenditure]

Q105[SQ004]. What are the categories of open government data (OGD) used at your institution? [Education]

Q105[SQ005]. What are the categories of open government data (OGD) used at your institution? [National statistics (demographic, economic indicators)]

Q105[SQ006]. What are the categories of open government data (OGD) used at your institution? [Financial]

Q105[SQ007]. What are the categories of open government data (OGD) used at your institution? [Expenditure]

Q105[SQ008]. What are the categories of open government data (OGD) used at your institution? [Geospatial (location-ZIP code and corresponding latitude and longitude coordinates, maps)]

Q105[SQ009]. What are the categories of open government data (OGD) used at your institution? [Infrastructure]

Q105[SQ010]. What are the categories of open government data (OGD) used at your institution? [Justice and security (prosecutions, crimes)] 
Table 6. Cont.

\section{Column Name}

Description

Datatype

Q105[SQ011]. What are the categories of open government data (OGD) used at your institution? [Legislative (laws, bills)]

Q105[SQ012]. What are the categories of open government data (OGD) used at your institution? [Environment (air or water quality, climate, pollution)]

Q105[SQ013]. What are the categories of open government data (OGD) used at your institution? [Budget]

Q105[SQ014]. What are the categories of open government data (OGD) used at your institution? [Planning]

Q105[SQ015]. What are the categories of open government data (OGD) used at your institution? [Territorial property]

Q105[SQ016]. What are the categories of open government data (OGD) used at your institution? [Business registration]

Q105[SQ017]. What are the categories of open government data (OGD) used at your institution? [Elections (results, candidates)]

Q105[SQ018]. What are the categories of open government data (OGD) used at your institution? [Health]

Q105[SQ019]. What are the categories of open government data (OGD) used at your institution? [Traffic]

Q105[SQ020]. What are the categories of open government data (OGD) used at your institution? [Transportation]

\begin{tabular}{lll}
\hline Column Name & Description & Datatype \\
\hline $\begin{array}{l}\text { Q1051. Are there other OGD categories used at your } \\
\text { workplace? }\end{array}$ & $\begin{array}{l}\text { Field to inform additional categories of open } \\
\text { government data (OGD) used }\end{array}$ & Text
\end{tabular}

Question Q104. What are the institutions/agencies that provide OGD used at your workplace? Q104 is mandatory when Q100 response $=$ Yes.

Q104. What are the institutions/agencies that provide Field to inform the names of the institutions that OGD used at your workplace? provide open government data (OGD)

Text

Question Q150. Why open government data are open government data not used? Optional multiple-choice question. Possible responses [Yes, No, N/A]. N/A = Not answered. Q150 is only presented when Q100 response <> Yes.

Column name and description

Q150[SQ002]. Why are open government data (OGD) not used in your institution? [There is no government/legal mandate to use OGD]

Q150[SQ003]. Why are open government data (OGD) not used in your institution? [No need to use OGD]

Q150[SQ004]. Why are open government data (OGD) not used in your institution? [I do not know OGD]

\begin{tabular}{lll} 
Column Name & Description & Datatype \\
$\begin{array}{l}\text { Q151. Are there other reasons open government data } \\
\text { are not used in your institution? }\end{array}$ & $\begin{array}{l}\text { Field to inform additional reasons why open } \\
\text { government data (OGD) are not used }\end{array}$ & Text \\
\hline
\end{tabular}

Question Q155. Could this questionnaire be sent to someone else? If so, please indicate this person's email in the comments field.

Datatype: text. Possible responses [Yes, No]. Q155 is mandatory when Q100 <> Yes.

Column name and description

Q155. Could this questionnaire be sent to someone else? If so, please indicate this person's email in the comments field.

Column Name Description Datatype

Q155[comment]. Could this questionnaire be sent to someone else? If so, please indicate this person's email Field to inform the email of additional respondents Text in the comments field. [Comment]

Table 7 presents the metadata of questions related to the benefits of using open government data (OGD) in the public sector. Benefits were grouped in three categories: political and social (BEPS), economic (BEE), and operational and technical (BEOT). Additionally, BEOTHER indicates the benefits suggested by the respondent. The last question in this table, Q160, investigates the negative impacts or effects of using OGD in the public sector. 
Table 7. Metadata of the benefits of using open government data.

\section{Benefits of Using Open Government Data}

All benefits questions are mandatory, except open-ended questions. Response datatype: text. Possible responses are in a five-point Likert scale [strongly disagree, disagree, neutral, agree, strongly agree]. Questions are only presented when Q100 = Yes. Column is empty if Q100 <> Yes.

Question BEE. What are the economic benefits of using open government data?

Column name and description

BEE[BEE02]. What are the economic benefits of using open government data? [Increased administrative efficiency]

BEE[BEE04]. What are the economic benefits of using open government data? [Offer of improved processes, products, and services]

BEE[BEE03]. What are the economic benefits of using open government data? [Reduced operating costs]

BEE[BEE01]. What are the economic benefits of using open government data? [Gained access to external capacity and resources for solving problems]

Question BEPS. What are the political and social benefits of using open government data?

Column name and description

BEPS[BEPS04]. What are the political and social benefits of using open government data? [Promotion of the principles and philosophy of Open Government]

BEPS[BEPS02]. What are the political and social benefits of using open government data? [Increased transparency]

BEPS[BEPS05]. What are the political and social benefits of using open government data? [Increased social control]

BEPS[BEPS06]. What are the political and social benefits of using open government data? [Increased civic participation and public engagement]

BEPS[BEPS03]. What are the political and social benefits of using open government data? [More informed citizens]

BEPS[BEPS01]. What are the political and social benefits of using open government data? [Increased intra-governmental confidence]

BEPS[BEPS07]. What are the political and social benefits of using open government data? [More efficient accountability]

BEPS[BEPS08]. What are the political and social benefits of using open government data? [Gained new knowledge and insights into the public sector]

Question BEOT. What are the technical and operational benefits realized by the use of open government data?

Column name and description

BEOT[BEOT05]. What are the technical and operational benefits realized by the use of open government data? [Development of improved public policies]

BEOT[BEOT03]. What are the technical and operational benefits realized by the use of open government data? [Increased intra-governmental collaboration]

BEOT[BEOT08]. What are the technical and operational benefits realized by the use of open government data? [New processes, products, and services developed]

BEOT[BEOT10]. What are the technical and operational benefits realized by the use of open government data? [Improved processes]

BEOT[BEOT06]. What are the technical and operational benefits realized by the use of open government data? [Improved data management]

BEOT[BEOT01]. What are the technical and operational benefits realized by the use of open government data? [Improved access to public services]

BEOT[BEOT07]. What are the technical and operational benefits realized by the use of open government data? [Increased efficiency in making changes in service delivery]

BEOT[ВЕОT09]. What are the technical and operational benefits realized by the use of open government data? [Decision-making process more informed]

BEOT[BEOT11]. What are the technical and operational benefits realized by the use of open government data? [Innovation support processes deployed] 
Table 7. Cont.

\section{Benefits of Using Open Government Data}

BEOT[BEOT02]. What are the technical and operational benefits realized by the use of open government data? [Increased problem-solving capacity]

BEOT[BEOT12]. What are the technical and operational benefits realized by the use of open government data? [Use of collective intelligence to solve a public problem]

Column Name
BEOTHER. Are there other benefits
promoted by the use of open government
data at your workplace?

Q160. Could the use of open government data (OGD) have negative effects or impacts (perceived or actual) on your institution? And on Government?

Description Datatype

Field to inform additional benefits of using open government data (OGD)

Text

Field to inform the respondent perception about negative impacts the use of OGD Text could cause

Table 8 displays metadata of barriers to OGD use in the public sector questions. Barriers' questions were categorized as cultural (BAC), economic and financial (BAEF), policy and legal (BAPL), organizational and institutional (BAOI), and operational and technical (BAOT). Additionally, BAOTHER indicates barriers suggested by the respondent.

Table 8. Metadata of the barriers to open government data use.

\begin{tabular}{|c|}
\hline Barriers to OGD Use \\
\hline $\begin{array}{l}\text { All barriers' questions are mandatory, except the open-ended questions. Response datatype: text. Possible responses are presented } \\
\text { in the five-point Likert scale [strongly disagree, disagree, neutral, agree, strongly agree]. Questions are only presented when Q100 = } \\
\text { Yes. Column is empty if Q100 <> Yes. }\end{array}$ \\
\hline Question BAC. What are the cultural barriers that hinder open government data use? \\
\hline Column name and description \\
\hline $\begin{array}{l}\text { BAC[BAC01]. What are the cultural barriers that hinder open government data use? [Management and public managers do not } \\
\text { know what open data is] }\end{array}$ \\
\hline $\begin{array}{l}\text { BAC[BAC02]. What are the cultural barriers that hinder open government data use? [Lack of organizational culture favorable to } \\
\text { open data] }\end{array}$ \\
\hline Question BAEF. What are the economic and financial barriers that hinder open government data use? \\
\hline Column name and description \\
\hline $\begin{array}{l}\text { BAEF[BAEF01]. What are the economic and financial barriers that hinder open government data use? [There is no budget, no } \\
\text { financial resources to use open data] }\end{array}$ \\
\hline $\begin{array}{l}\text { BAEF[BAEF03]. What are the economic and financial barriers that hinder open government data use? [Cost to hire people able to } \\
\text { use open data is very high] }\end{array}$ \\
\hline Question BAPL. What are the legal and public policy-related barriers that hinder open government data use? \\
\hline Column name and description \\
\hline $\begin{array}{l}\text { BAPL[BAPL03]. What are the legal and public policy-related barriers that hinder open government data use? [Open data policy is } \\
\text { inadequate or/and doesn't exist] }\end{array}$ \\
\hline $\begin{array}{l}\text { BAPL[BAPL04]. What are the legal and public policy-related barriers that hinder open government data use? [Open data use laws } \\
\text { are inadequate or lacking] }\end{array}$ \\
\hline $\begin{array}{l}\text { BAPL[BAPL05]. What are the legal and public policy-related barriers that hinder open government data use? [Open data use } \\
\text { standards and guidelines are inadequate or/and do not exist] }\end{array}$ \\
\hline $\begin{array}{l}\text { BAPL[BAPL06]. What are the legal and public policy-related barriers that hinder open government data use? [Use license does } n \\
\text { exist, or unclear, or restrict use] }\end{array}$ \\
\hline
\end{tabular}


Table 8. Cont.

\section{Barriers to OGD Use}

Question BAOI. What are the organizational and/or institutional barriers that hinder open government data use?

Column name and description

BAOI[BAOI12]. What are the organizational and/or institutional barriers that hinder open government data use? [Benefits and impacts of using open data are unclear]

BAOI[BAOI09]. What are the organizational and/or institutional barriers that hinder open government data use? [No support for innovation]

BAOI[BAOI02]. What are the organizational and/or institutional barriers that hinder open government data use? [The organizational structure does not support the use of open data]

BAOI[BAOI04]. What are the organizational and/or institutional barriers that hinder open government data use? [The organization does not have the organizational capabilities, routines, and processes to use the data]

BAOI[BAOI08]. What are the organizational and/or institutional barriers that hinder open government data use? [There are no human resources with the knowledge, skills, and/or capabilities to use open data]

BAOI[BAOI07]. What are the organizational and/or institutional barriers that hinder open government data use? [There is no definition of competencies for the use of open data]

BAOI[BAOI06]. What are the organizational and/or institutional barriers that hinder open government data use? [Lack of non-financial resources (time, equipment, etc.) to use open data]

Question BAPS. What are the political and social barriers that hinder open government data use?

Column name and description

BAPS[BAPS01]. What are the political and social barriers that hinder open government data use? [Open data is not a political priority]

BAPS[BAPS02]. What are the political and social barriers that hinder open government data use? [Strategy and/or leadership do not support open data use]

Question BAOT. What are the technical and operational barriers that hinder open government data use?

Column name and description

BAOT[BАОT01]. What are the technical and operational barriers that hinder open government data use? [There is no centralized portal or open data infrastructure]

BAOT[BAOT02]. What are the technical and operational barriers that hinder open government data use? [Difficulty in discovering/locating data]

BAOT[BАOT03]. What are the technical and operational barriers that hinder open government data use? [Data availability issues]

BAOT[BAOT04]. What are the technical and operational barriers that hinder open government data use? [Data accessibility issues]

BAOT[BAOT05]. What are the technical and operational barriers that hinder open government data use? [Poor data quality (incomplete, inaccurate, obsolete, and/or inconsistent)]

BAOT[BАОT06]. What are the technical and operational barriers that hinder open government data use? [Low data usability (fragmented data, no default for open data, file-owning format)]

BAOT[BАOT08]. What are the technical and operational barriers that hinder open government data use? [Data are not compatible and cannot be compared]

BAOT[BАOT09]. What are the technical and operational barriers that hinder open government data use? [Data cannot be combined and connected]

BAOT[BAOT10]. What are the technical and operational barriers that hinder open government data use? [Data are not sustained or maintained]

BAOT[BАOT11]. What are the technical and operational barriers that hinder open government data use? [Data sources are unreliable]

BAOT[BAOT12]. What are the technical and operational barriers that hinder open government data use? [Results obtained from different sources differ]

BAOT[BAOT13]. What are the technical and operational barriers that hinder open government data use? [Uploading data are not supported] 
Table 8. Cont.

\section{Barriers to OGD Use}

BAOT[BAOT14]. What are the technical and operational barriers that hinder open government data use? [No processing power]

BAOT[BAOT15]. What are the technical and operational barriers that hinder open government data use? [Lack of proper tools to manipulate data]

BAOT[BAOT16]. What are the technical and operational barriers that hinder open government data use? [Lack of support for tools or help desk]

BAOT[BAOT17]. What are the technical and operational barriers that hinder open government data use? [Difficulties to interact with the data provider]

Column Name Description Datape

BAOTHER. Are there other real or potential barriers that prevent or hinder the use of open government data in your work context?
Field to inform additional barriers to

open government data (OGD) use
Text

The questions about enablers of OGD use in the public sector are presented in Table 9. They were grouped into in the same categories listed for OGD use barriers, i.e., cultural (EC), economic and financial (EEF), policy and legal (EPL), organizational and institutional (EOI), and operational and technical (EOT). Additionally, EOTHER holds enablers suggested by the respondent.

Table 9. Metadata of the enablers of open government data use.

\section{Enablers of OGD Use}

All enablers' questions are mandatory, except the open-ended questions. Response datatype: text. Possible responses are shown in a five-point Likert scale [strongly disagree, disagree, neutral, agree, strongly agree]. Questions are only presented when Q100 = Yes. Column is empty if Q100 <> Yes.

Question EC. What are the cultural factors that facilitate, enable, or allow the use of open government data?

Column name and description

EC[EC01]. What are the cultural factors that facilitate, enable, or allow the use of open government data? [Organizational culture enables the use of open data]

EC[EC02]. What are the cultural factors that facilitate, enable, or allow the use of open government data? [Existence of cooperative work culture]

Question EEF. What are the economic and financial factors that facilitate, enable, or allow open government data use?

Column name and description

EEF[EEF01]. What are the economic and financial factors that facilitate, enable, or allow open government data use? [Financial resources are available to support the use of open data]

Question EPL. What are the public policy and legal factors that facilitate, enable, or allow open government data use?

Column name and description

EPL[EPL02]. What are the public policy and legal factors that facilitate, enable, or allow open government data use? [Public open data policy exists]

EPL[EPL03]. What are the public policy and legal factors that facilitate, enable, or allow open government data use? [Laws governing the use of open data exist]

EPL[EPL04]. What are the public policy and legal factors that facilitate, enable, or allow open government data use? [Regulations and open data standards exist]

EPL[EPL01]. What are the public policy and legal factors that facilitate, enable, or allow open government data use? [There is legal compliance pressure]

Question EOI. What are the organizational and/or institutional factors that facilitate, enable, or allow open government data use? 
Table 9. Cont.

\section{Enablers of OGD Use}

Column name and description

EOI[EOI01]. What are the organizational and/or institutional factors that facilitate, enable, or allow open government data use?

[The Administration promotes and internally discloses the use of open data]

EOI[EOI02]. What are the organizational and/or institutional factors that facilitate, enable, or allow open government data use? [There have been changes in the organizational structure to support open data]

EOI[EOI03]. What are the organizational and/or institutional factors that facilitate, enable, or allow open government data use? [The organization has the ability to digitize]

EOI[EOI04]. What are the organizational and/or institutional factors that facilitate, enable, or allow open government data use? [Managers are motivated to use open data]

Question EPS. What are the political and social factors that facilitate, enable, or allow open government data use?

Column name and description

EPS[EPS01]. What are the political and social factors that facilitate, enable, or allow open government data use? [Political leadership committed to the use of open data]

EPS[EPS02]. What are the political and social factors that facilitate, enable, or allow open government data use? [Management and public managers are aware of the existence of open data]

EPS[EPS03]. What are the political and social factors that facilitate, enable, or allow open government data use? [External stakeholders (international bodies, journalists) disseminate and promote the use of open data]

Question EOT. What are the operational and technical factors that facilitate, enable, or allow open government data use?

Column name and description

EOT[EOT01]. What are the operational and technical factors that facilitate, enable, or allow open government data use? [There are open data portals and infrastructure]

EOT[EOT02]. What are the operational and technical factors that facilitate, enable, or allow open government data use? [Case studies and examples are available in the Open Data Portal]

EOT[EOT03]. What are the operational and technical factors that facilitate, enable, or allow open government data use? [Portal provides facilities for searching/searching for open data]

EOT[EOT04]. What are the operational and technical factors that facilitate, enable, or allow open government data use?

[High-quality data is available]

EOT[EOT05]. What are the operational and technical factors that facilitate, enable, or allow open government data use? [Metadata is provided with the data]

EOT[EOT06]. What are the operational and technical factors that facilitate, enable, or allow open government data use? [Data do not violate privacy laws]

EOT[EOT07]. What are the operational and technical factors that facilitate, enable, or allow open government data use? [Data are improved]

EOT[EOT08]. What are the operational and technical factors that facilitate, enable, or allow open government data use? [Data are maintained]

EOT[EOT09]. What are the operational and technical factors that facilitate, enable, or allow open government data use? [Tools and mechanisms to work with open data are available]

EOT[EOT10]. What are the operational and technical factors that facilitate, enable, or allow open government data use? [The use of the data is monitored]

EOT[EOT11]. What are the operational and technical factors that facilitate, enable, or allow open government data use? [There are public/private partnerships that support the use of open data]

Column Name Description Datape

EOTHER. Are there other real or potential factors that facilitate, enable, or allow open government data use in your work context?
Field to inform additional facilitators to open government data (OGD) use
Text 
Drivers of OGD use in the public sector are listed in Table 10. As with the previous questions, they were categorized into organizational and institutional (DOI), political and social (DPS), and operational and technical (DOT). Additionally, DOTHER holds drivers suggested by the respondent. The final considerations section CF01 asks if the respondent wants to comment on the OGD use.

Table 10. Metadata of the drivers of open government data use.

\section{Drivers of Open Government Data Use}

All drivers' questions are mandatory, and exceptions are the open-ended questions. Response datatype: text. Possible responses are listed in a five-point Likert scale [strongly disagree, disagree, neutral, agree, strongly agree]. Questions are only presented when Q100 = Yes. Column is empty if Q100 <> Yes.

Question DOI. What are the organizational and/or institutional factors that drive open government data use?

Column name and description

DOI[DOI01]. What are the organizational and/or institutional factors that drive open government data use? [The Administration and public managers understand the benefits and impacts promoted by the use of open data]

DOI[DOI02]. What are the organizational and/or institutional factors that drive open government data use? [Open data use is institutionalized in the administration]

DOI[DOI04]. What are the organizational and/or institutional factors that drive open government data use? [The existence of intermediaries adds knowledge and capacity for the use of open data]

Question DPS. What are the political and social factors that drive open government data use?

Column name and description

DPS[DPS01]. What are the political and social factors that drive open government data use? [External stakeholders (international bodies, other bodies, journalists) press the Administration to use the open data]

Question DOT. What are the technical and operational factors that drive open government data use?

Column name and description

DOT[DOT03]. What are the technical and operational factors that drive open government data use? [Existence of historical data]

DOT[DOT06]. What are the technical and operational factors that drive open government data use? [Data are available in user-friendly formats]

\begin{tabular}{lll}
\hline Column Name & Description & Datatype \\
\hline
\end{tabular}

DOTHER. Are there other real or potential factors that drive the use of open government data in your work

Field to inform additional drivers of open government data use

Text context?

Final considerations

\begin{tabular}{lll}
\hline Column Name & Description & Datatype \\
\hline $\begin{array}{l}\text { CF01. Would you like to make any } \\
\text { general comments about using open } \\
\text { government data? }\end{array}$ & $\begin{array}{l}\text { Field to collect additional comments } \\
\text { related to the use of open government } \\
\text { data }\end{array}$ & Text \\
\hline
\end{tabular}

\section{Results, Limitations, and Conclusions}

This research aims to answer whether, how, and why OGD is used in the Brazilian states and District public administrations. Figure 1 shows that 26 out of the 27 Federation Units participated in the survey. Only the State of São Paulo did not respond to the questionnaire. Moreover, the map indicates that 16 States use/reuse OGD. The respondent of one State (Minas Gerais) reported not knowing whether OGD was used. The remaining nine federation units informed that OGD was not used. Therefore, $61 \%$ of the States' administrations use OGD, 35\% do not use it, and $4 \%$ do not know whether these data are used. 


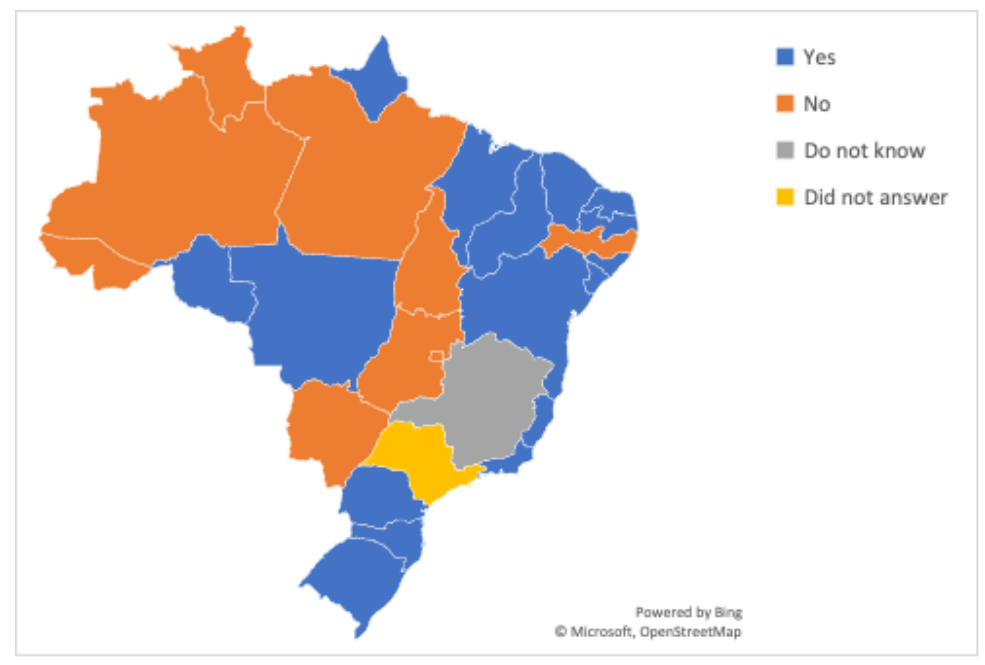

Figure 1. Are open government data used/reused?

Regarding how OGD is used, we conclude that data are mainly used to support decision-making, create/improve public services, and analyze data (create analyses, forecasts, estimates, simulations, models). The most popular OGD categories mentioned by $63 \%$ of respondents are procurement and bids, expenses, and budget. The most cited data sources were the state secretariats and the Brazilian Institute of Geography and Statistics (IBGE).

The question of why OGD is used was addressed in terms of what OGD use benefits, barriers, facilitators, and drivers are. The most prominent benefits reported were increased transparency, more informed citizens, increased efficiency of the administration, and a more informed decision-making process. The most significant OGD use barriers were "the administration and public managers do not know what open data are" and "the absence of an organizational culture favorable to open data". Regarding facilitating factors, the most relevant facilitators were "data were improved" and "the existence of a cooperative work culture". Finally, the most important drivers were "data are available in easy-touse formats" and "external stakeholders (international bodies, other agencies, journalists) pressure the administration to use the open data".

It is worth noting that the reported results present a partial view of the use of OGD, as only one response per federation unit was considered. Thus, other secretaries and state agencies should be surveyed to acquire a broader view of OGD use and reuse in the Brazilian state and district administrations. However, public managers can use these results as a starting point to inform decision-making regarding open data policy and digital governance.

Furthermore, the usefulness of this dataset could be verified by developing indicators to measure its utilization rate using data collected by the data repository about downloads and reads.

Supplementary Materials: The following supporting information is available online at https:/ doi.org/ 10.34622/datarepositorium/UY7MFA, Table S1: Information about the dataset, Table S2: Dataset in Portuguese, Table S3: Metadata in Portuguese, Table S4: Dataset in English, Table S5: Metadata in English, and Table S6: Excel spreadsheet with all data and metadata.

Author Contributions: Conceptualization: A.A.B., D.S. and I.K.; questionnaire development A.A.B. and I.K.; investigation, writing—original draft preparation, I.K.; writing—review and editing: A.A.B. and D.S.; supervision: A.A.B. and D.S. All authors have read and agreed to the published version of the manuscript.

Funding: This research received no external funding. 
Institutional Review Board Statement: This research is approved by University of Minho Ethics Committee (CEICSH 069/2021).

Informed Consent Statement: The following statement was presented to respondents so to acquire their consent to participate in the survey: "Please read this consent form carefully before deciding to participate in the study. Time required: It takes around about 20 minutes to answer this questionnaire. Risks: The risks associated with participating in this study are minimal. Benefits: The benefits associated with this study are related to acquiring new knowledge and insights about the processes and procedures adopted by the Brazilian states and federal district public administrations in using open data to promote greater transparency and efficiency using these data. Confidentiality: The University of Minho (UM), based in R. 4710-057, Braga Portugal, under the General Data Protection Law of Brazil (LGPD), Law 13.709/2018, collects the personal data requested in this form to complement the analysis of how open government data are used by the public sector, and ensures that it will use this information exclusively for this purpose and after fulfilling the purposes the data will be erased. UM has adopted the best practices and organizational techniques to protect your personal data, as well as guarantee the exercise of your rights of access, rectification, and opposition, through the email: ikawashi@gmail.com. I authorize the use of the data provided herein in the context of the study of the use of public sector open government data that is being conducted by UM and UNU-EGOV in collaboration with the GTD.GOV. Voluntary Participation: Your participation in the study is entirely voluntary".

Data Availability Statement: The resulting dataset is available at: https://doi.org/10.34622 / datarepositorium/UY7MFA as per the CC0— "Public Domain Dedication" License, accessed on 5 October 2021.

Conflicts of Interest: The authors declare no conflict of interest.

\section{References}

1. Charalabidis, Y.; Zuiderwijk, A.; Alexopoulos, C.; Janssen, M.; Lampoltshammer, T.; Ferro, E. The World of Open Data: Concepts, Methods, Tools and Experiences; Springer International Publishing: Cham, Switzerland, 2018; Volume 28. [CrossRef]

2. Carrara, W.; Sander, F.; Oudkerk, F.; van Steenbergen, E.; Tinholt, D. Analytical Report 1: Digital Transformation and Open Data. Publications Office, LU. 2020. Available online: https://data.europa.eu/doi/10.2830/673557 (accessed on 1 October 2021).

3. Khurshid, M.M.; Zakaria, N.H.; Rashid, A.; Ahmad, M.N.; Arfeen, M.I.; Faisal Shehzad, H.M. Modeling of Open Government Data for Public Sector Organizations Using the Potential Theories and Determinants-A Systematic Review. Informatics 2020, 7, 24. [CrossRef]

4. Zuiderwijk, A.; de Reuver, M. Why open government data initiatives fail to achieve their objectives: Categorizing and prioritizing barriers through a global survey. Transform. Gov. People Process Policy 2021, 15, 377-395. [CrossRef]

5. Crusoe, J.; Melin, U. Investigating Open Government Data Barriers: A Literature Review and Conceptualization; Lecture Notes in Computer Science (including subseries Lecture Notes in Artificial Intelligence and Lecture Notes in Bioinformatics), LNCS; Springer: Berlin/Heidelberg, Germany, 2018; Volume 11020, pp. 169-183. [CrossRef]

6. Mesquita, M.A.; Luciano, E.M.; Lübeck, R.; Wiedenhöft, G. Discussing the Twofold Role of Government-Provider and User-In the Open Government Data Ecosystem. In Proceedings of the EGov-CEDEM-EPart, Linköping, Sweden, August 2020.

7. ABEP-TIC. GTD.gov: Grupo de Transformação Digital. 2020. Available online: https://gtdgov.org.br/quem-somos (accessed on 1 October 2021).

8. ABEP-TIC. ABEP-Associação Brasileira de Entidades Estaduais de Tecnologia da Informação e Comunicação. 2017. Available online: https: / / www.abep-tic.org.br/sobre (accessed on 5 October 2021).

9. CONSAD. Conselho Nacional de Secretários de Estado da Administração-CONSAD. 2021. Available online: https://www. consad.org.br/consad/ (accessed on 5 October 2021).

10. Instituto Brasileiro de Geografia e Estatísticas. ESTADIC-Pesquisa de Informações Básicas Estaduais 2019; Instituto Brasileiro de Geografia e Estatísticas: Rio de Janeiro, Brazil, 2020. Available online: https://biblioteca.ibge.gov.br/visualizacao/livros/liv101 769.pdf (accessed on 13 September 2021).

11. Lafuente, M.; Leite, R.; Porrúa, M.; Valenti, P. Transformação Digital dos Governos Brasileiros: Tendências na Transformação Digital em Governos Estaduais e no Distrito Federal do Brasil; Banco Interamericano de Desenvolvimento: Washington, DC, USA, 2021.

12. Kalaian, S.A. Research Design. In Encyclopedia of Survey Research Methods; Lavrakas, P., Ed.; Sage Publications, Inc.: Thousand Oaks, CA, USA, 2008. [CrossRef]

13. Moher, D.; Shamseer, L.; Clarke, M.; Ghersi, D.; Liberati, A.; Petticrew, M.; Shekelle, P.; Stewart, L.A.; PRISMA-P Group. Preferred reporting items for systematic review and meta-analysis protocols (PRISMA-P) 2015 statement. Syst. Rev. 2015, 4, 1. [CrossRef] [PubMed]

14. Kitchenham, B.; Brereton, O.P.; Budgen, D.; Turner, M.; Bailey, J.; Linkman, S. Systematic literature reviews in software engineering-A systematic literature review. Inf. Softw. Technol. 2009, 51, 7-15. [CrossRef] 
15. Kawashita, I.; Baptista, A.A.; Soares, D.S. Open Government Data Use by the Public Sector-an Overview of its Benefits, Barriers, Drivers, and Enablers. In Proceedings of the 55th Hawaii International Computer Science Conference, Kauai, HI, USA, 1 January 2022; p. 10.

16. Kalton, G. Nonprobability Sampling. In Introduction to Survey Sampling; SAGE Publications, Inc.: Thousand Oaks, CA, USA, 1983. [CrossRef]

17. Chromy, J.R. Snowball Sampling. In Encyclopedia of Survey Research Methods; Lavrakas, P., Ed.; Sage Publications, Inc.: Thousand Oaks, CA, USA, 2008. [CrossRef]

18. Kawashita, I.; Baptista, A.A.; Soares, D.S. Use of Open Government Data in the Brazilian States and Federal District Public Administrations. Centro de Investigação Algoritmi. 2021. Available online: https:// datarepositorium.uminho.pt/dataset.xhtml? persistentId=doi:10.34622/datarepositorium/UY7MFA (accessed on 23 December 2021). 